\title{
Survey Kepuasan Masyarakat Terhadap Pelayanan Di UPT Dinas Pendapatan Provinsi Riau
}

\author{
MACHASIN \\ AHMAD RIFQI \\ Fakultas Ekonomi Universitas Riau Pekanbaru \\ Kampur Jalan Binawidya Panam
}

\begin{abstract}
This research was conducted aimed to measure the extent of public satisfaction with the services performed by the Riau Provincial Revenue Office with the policy of the Minister of State Apparatus No. 16 of 2014 on Public Satisfaction Survey guidelines for the implementation of the Public as necessary to build public confidence in the apparatus as publik services providers in order to improve the welfare of society. Samples of this study consisted of 17 UPT Riau Provincial Revenue Service with analytic descriptive analysis techniques. Results of this study result unit within the overall service of the Provincial Revenue Service is very good with service quality category A (Excellent) with a value of 89.76 .
\end{abstract}

Keywords: Satisfaction, Service, Riau, Apparatus, Public

Reformasi pemerintahan daerah melalui pemberlakuan UU 22/1999 tentang Pemerintahan Daerah yang kemudian digantikan dengan UU 32/2004 tentang Pemerintahan Daerah telah membawa pengaruh yang signifikan dalam penyediaan pelayanan publik. Hal ini ditandai dengan diberikannya kewenangan yang lebih besar kepada daerah untuk mengatur dan mengurus rumah tangganya sendiri. Karenanya, dengan otonomi daerah itu telah memberikan peluang kepada daerah untuk melaksanakan pembangunannya sesuai dengan kebutuhan dan kondisi yangProvinsi ada di wilayahnya.

Terkait dengan pemberlakuan UU 32/2004 tentang Pemerintahan Daerah, sejumlah daerah terbukti mampu memanfaatkan peluang yang diberikan dengan baik serta berhasil dalam meningkatkan kesejahteraan masyarakatnya dan dalam meningkatkan pelayanan publik kepada masyarakatnya. Keberhasilan daerah-daerah tersebut telah memberikan harapan dan kepercayaan besar bagi masyarakatnya. Terbukti dengan adanya kemenangan yang diperoleh para kepala daerah di daerah-daerah tersebut dalam Pemilihan Kepala daerah yang dilakukan secara langsung. Masyarakat setempat memiliki harapan yang besar akan kemajuan program-program yang telah dilaksanakannya selama ini. Karenanya, masyarakat menaruh kepercayaan dengan memilih kembali kepala daerah yang dinilainya telah berhasil tersebut.

Dalam rangka meningkatkan kualitas pelayanan publik secara berkelanjutan, Pemerintah perlu mengevaluasi terhadap penyelenggaraan pelayanan publik. Pemerintah melalui Menteri Pendayagunaan Aparatur Negara (MENPAN) telah mengeluarkan kebijakan pendayagunaan aparatur Negara bidang pelayanan publik melalui Keputusan Menteri Negara Pendayagunaan Aparatur Negara (MENPAN) Nomor: 16 Tahun 2014 tentang Pedoman Survei Kepuasan Masyarakat Terhadap Penyelenggaraan Publik.

Kebijakan tersebut dibuat dalam merespon keluhan dan tuntutan masyarakat terhadap kualitas pelayanan publik yang ada di semua unit pelayanan milik pemerintah. Pelayanan publik oleh aparatur negara dewasa ini telah menjadi isu strategis, karena tingkat kualitas kinerja pelayanan publik akan menentukan baik 
buruknya pelayanan kepada masyarakat dan pada gilirannya akan menentukan citra dari aparatur negara. Pelayanan publik pada dasarnya menyangkut aspek kehidupan yang sangat luas. Dalam kehidupan bernegara, maka pemerintah memiliki fungsi memberikan berbagai pelayanan publik yang diperlukan oleh masyarakat, mulai dari pelayanan dalam bentuk pengaturan atau pun pelayanan-pelayanan lain dalam rangka memenuhi kebutuhan masyarakat. Berbagai keluhan masyarakat atas rendahnya kinerja pelayanan yang diberikan oleh pemerintah daerah baik pelayanan di bidang perizinan, administrasi, pelayanan kesehatan di Puskesmas ataupun di Rumah sakit termasuk pelayanan oleh Badan Usaha Milik Daerah, perlu segera diupayakan perbaikannya. Keluhan masyarakat yang tidak segera direspon oleh pemerintah akan dapat menimbulkan citra yang kurang baik terhadap aparatur pemerintah.

Maksud dari pelaksanaan kegiatan Survey Kualitas Layanan UPT Dinas Pendapatan Provinsi Riau dalam rangka pemenuhan penyelenggaraan pelayanan publik secara prima dengan serangkaian petunjuk tertulis yang baku dan terinci kepada penyelenggara dalam memberikan pelayanan administratif, sistematis untuk memperoleh hasil kerja tertentu dalam melayani masyarakat.

Tujuan dari pelaksanaan kegiatan Survey Kualitas Layanan UPT Dinas Pendapatan Provinsi Riau adalah untuk mengukur kepuasan masyarakat sebagai pengguna layanan dan meningkatkan kualitas pelayanan publik karena diperlukan untuk membangun kepercayaan masyarakat terhadap aparatur sebagai penyedia pelayanan publik dalam rangka peningkatan kesehjateraan masyarakat dengan menjadikan penilaian masyarakat sebagai sarana untuk melakukan perbaikan pelayanan publik.

Sasaran yang ingin dicapai dari kegiatan ini adalah : 1) terwujudnya peningkatan kualitas pelayanan publik pada UPT dilingkungan Dinas Pendapatan
Provinsi Riau; 2) terwujudnya kepercayaan masyarakat terhadap aparatur Dinas Pendapatan Provinsi Riau sebagai penyedia pelayanan publik. Output yang ingin diperoleh dari pelaksanaan kegiatan ini adalah Laporan yang disampaikan dalam bentuk hardcopy dan softcopy yang berisikan Hasil Penilaian Survey Kepuasan masyarakat terhadap penyelenggaraan pelayanan public di 17 UPT di Lingkungan Dinas Pendapatan Provinsi Riau dan disertai Rekomendasi langkah-langkah perbaikan pelayanan.

Kepuasan masyarakat merupakan faktor yang sangat penting dan menentukan keberhasilan suatu badan usaha karena masyarakat adalah konsumen dari produk yang dihasilkannya. Hal ini didukung oleh pernyataan Hoffman dan Beteson (1997, p.270), yaitu : "without custumers, the service firm has no reason to exist". Definisi kepuasan masyarakat menurut Mowen (1995, p.511): "Costumers satisfaction is defined as the overall attitudes regarding goods or services after its acquisition and uses". Oleh karena itu, badan usaha harus dapat memenuhi kebutuhan dan keinginan masyarakat sehingga mencapai kepuasan masyarakat dan lebih jauh lagi kedepannya dapat dicapai kesetiaan masyarakat. Sebab, bila tidak dapat memenuhi kebutuhan dan kepuasan masyarakat sehingga menyebabkan ketidakpuasan masyarakat mengakibatkan kesetiaan masyarakat akan suatu produk menjadi luntur dan beralih ke produk atau layanan yang disediakan oleh badan usaha yang lain.

Menurut Mendelsohn (1998, p.42) ada 2 keuntungan bagi badan usaha dengan adanya kepuasan masyarakat, yaitu : "First, retaining customers is less expensive than acquiring new ones. Second, increasing competition in the form of product, organizations, and distributing outlets means fierce pressure for costumers. And costumners satisfaction is viable strategy to maintain market share against the competitions". 
Terdapat sejumlah definisi mengenai Pelayanan Publik. Lonsdaledan Enyedi misalnya, mengartikan service sebagai assisting or benefiting individuals through making useful things available to them. Sedangkan public service diberi makna sebagai something made available to the whole of population, and it involves things which people can not normally provide for themselves i.e. people must act collectively (Lonsdaleand Enyedi, 1991 dalam Zauhar, 2001). Dengan demikian dapat dikatakan bahwa pelayanan publik merupakan suatu upaya membantu atau memberi manfaat kepada publik melalui penyediaan barang dan atau jasa yang diperlukan oleh mereka (Zauhar, 2001).

Mengingat sektor publik sangat terkait dengan keberadaan pemerintah, maka pelayanan publik juga dapat disamakan dengan terminologi pelayanan pemerintah (government service) yang diartikan sebagai pemberian pelayanan oleh agen pemerintah melalui pegawainya (the delivery of a service by a government agency using its own employees (Savas, 1987 dalam Zauhar, 2001). Negara dan sistem pemerintahan menjadi tumpuan pelayanan warga negara dalam memperoleh jaminan atas hak-haknya, karenanya peningkatan kualitas pelayanan (quality of service) akan semakin penting (Zauhar, 2001). Davidow (dalam Lovelock, 1988) menyebutkan bahwa pelayanan adalah halhal yang jika diterapkan terhadap suatu produk akan meningkatkan daya atau nilai terhadap pelanggan (service is those thing which when added to a product,increase its utility or value to the customer). Lebih lanjut Lovelock (1988) menyebutkan bahwa pelayanan yang baik membutuhkan instruktur pelayanan yang sangat baik pula. Hal yang paling penting adalah membuat setiap orang dalam organisasi berfokus pada kualitas. (Zauhar, 2001).

Crosby, Lehtimendan Wyckoff (dalam Lovelock,1988) mendefinisikan kualitas pelayanan sebagai berikut: "Penyesuaian terhadap perincian-perincian (conformance to specification) dimana kualitas ini dipandang sebagai derajat keunggulan yang ingin dicapai, dilakukannya kontrol terus menerus dalam mencapai keunggulan tersebut dalam rangka memenuhi kebutuhan pengguna jasa". (Zauhar, 2001). Penentuan kualitas pelayanan inilah yang tidak mudah. Lucy Gaster (1995 : 35) mengemukakan bahwa kesulitan menetapkan kualitas pelayanan disebabkan adanya berbagai dimensi perbedaan; antara harapan dan kenyataan, kepentingan warga negara secara langsung dengan kepentingan pemerintah atau produsen secara tidak langsung. Karena itulah diperlukan penentuan standarisasi kualitas pelayanan dalam berbagai dimensi secara cermat, dan merepresentasikan kebutuhan masyarakat di daerah yang bersangkutan.

Pelayanan merupakan respons terhadap kebutuhan manajerial yang hanya akan terpenuhi kalau pengguna jasa itu mendapatkan produk yang mereka inginkan (Lovelock,1988). Jika demikian halnya maka apa yang menjadi perumpamaan bahwa pembeli adalah raja (the customer is always right) menjadi sangat penting dan menjadi konsep yang mendasar bagi peningkatan manajemen pelayanan. (Zauhar, 2001).

Sejalan dengan pemikiran di atas, menurut Kotler (1995), kepuasan pelanggan terhadap suatu barang atau jasa dipengaruhi oleh tingkat perasaan seseorang setelah membandingkan kinerja (atau hasil) yang dirasakannya dilengkapi pengharapan. Karena tentunya seseorang akan merasa puas bila tercukupi rasa pengharapan terhadap sesuatu. Ada 4 (empat) metode untuk mengukur kepuasan pelanggan menurut Kotler: pertama, sistem keluhan dan saran (melalui kotak surat, surat pembaca, dll), kedua, survei kepuasan pelanggan di unit pelayanan, ketiga belanja siluman, dengan cara belanja untuk mengukur pelayanan tertentu dan keempat analisa kehilangan, untuk mengukur 
kecepatan dan keakuratan pelayanan kehilangan.

Selain itu, Tjiptono

menyebutkan bahwa kualitas memiliki hubungan yang erat dengan kepuasan pelanggan. Kualitas memberikan suatu dorongan kepada pelanggan untuk menjalin ikatan hubungan yang kuat dengan perusahaan/organisasi. Dalam jangka panjang, ikatan seperti ini memungkinkan perusahaan/organisasi untuk memahami dengan seksama harapan pelanggan serta kebutuhan mereka.

\section{Dengan}

demikian

perusahaan/organisasi dapat meningkatkan kepuasan pelanggan dengan cara memaksimumkan pengalaman pelanggan yang menyenangkan dan meminimumkan atau meniadakan pengalaman pelanggan yang kurang menyenangkan. Pada gilirannya kepuasan pelanggan dapat menciptakan kesetiaan atau loyalitas pelanggan kepada perusahaan/organisasi yang memberikan kualitas yang memuaskan.

Perusahaan/organisasi juga dapat meningkatkan pangsa pasarnya memenuhi pemenuhan kualitas yang bersifat customerdriven. Hal ini akan memberikan keunggulan harga dan customer value. Customer value merupakan kombinasi dari manfaat dan pengorbanan yang terjadi apabila pelanggan menggunakan suatu barang atau jasa guna memenuhi kebutuhan tertentu. Bila kualitas yang dihasilkan superior dan pangsa pasar yang dimiliki besar, maka profitabilitasnya terjamin. Jadi, ada kaitan yang erat antara kualitas dan profitabilitas.

Terkait dengan kondisi di atas, menurut Zeithamal, Parasuraman dan Berry (1990), harapan konsumen terhadap kualitas pelayanan sangat dipengaruhi oleh informasi yang diperoleh dari mulut ke mulut, kebutuhan konsumen itu sendiri, pengalaman masa lalu dalam mengonsumsi suatu produk hingga pada komunikasi eksternal melalui iklan. Bentuk pelayanan yang maksimal merupakan kepuasan bagi pelanggan. Sehingga, tuntutan terhadap kepuasan merupakan hal yang lumrah. Zeithamal, Parasuraman dan Berry juga menyatakan bahwa dalam menilai kualitas jasa/pelayanan, terdapat sepuluh ukuran kualitas jasa/ pelayanan, yaitu : 1) Tangible (nyata/berwujud); 2) Reliability (keandalan); 3) Responsiveness (Cepat tanggap); 4) Competence (kompetensi); 5) Access (kemudahan); 6) Courtesy (keramahan); 7) Communication (komunikasi); 8) Credibility (kepercayaan); 9) Security (keamanan); dan 10) Understanding the Customer (Pemahaman pelanggan).

\section{METODE}

Yang menjadi objek dari kegiatan adalah Wajib Pajak pada UPT dilingkungan Dinas Pendapatan Provinsi Riau. Dalam penyusunan laporan dilakukan dengan metode eksploratif, sedangkan dalam prosesnya mengikuti proses perencanaan normatif yang dimulai dengan pengumpulan data, dilanjutkan dengan pengolahan dan analisis data secara statistik. Populasi dalam survey indeks kepuasan masyarakat adalah Pengunjung di UPT Dinas Pendapatan Provinsi Riau. Sampel diambil dari pengunjung UPT yang datang dengan jumlah sampel sebanyak 2.040 Orang responden, dengan rincian setiap UPT terdiri dari 120 responden. Metode penentuan jumlah sampel adalah berdasarkan ("jumlah unsur variabel" +1$) \times 10=(9+1) \times 10=$ 100 responden. Namun dalam penelitian survei Indeks Kepuasan Masyarakat ini diambil sampel sebanyak 120 responden. Teknik pengumpulan data dilakukan melalui pengisian kuesioner dengan cara dilakukan oleh pencacah/petugas melalui wawancara. Instrumen yang dipergunakan dalam survei Indeks Kepuasan Masyarakat adalah berupa kuesioner.

Data mentah yang sudah terkumpul selama observasi perlu diperiksa lebih lanjut untuk memastikan data tidak ada yang tercecer atau tidak lengkap sehingga proses analisa data dapat dilakukan. Data 
dianalisa secara deskriptif analitik. Berikut ini di lingkungan Dinas Pendapatan Provinsi proses pengolahan data hasil survei IKM. Riau sebagai berikut

Nilai IKM dihitung dengan menggunakan "nilai rata-rata tertimbang" masing-masing unsur pelayanan. Dalam penghitungan indeks kepuasan masyarakat terhadap 9 unsur pelayanan yang dikaji, setiap unsur pelayanan memiliki penimbang yang sama dengan rumus sebagai berikut:

Bobot nilai rata - rata tertimbang $=\frac{\text { Jumlah Bobot }}{\text { Jumlah Unsur }}=\frac{1}{9}=0.111$

Untuk memperoleh nilai IKM unit pelayanan UPT digunakan pendekatan nilai rata-rata tertimbang dengan rumus sebagai berikut:

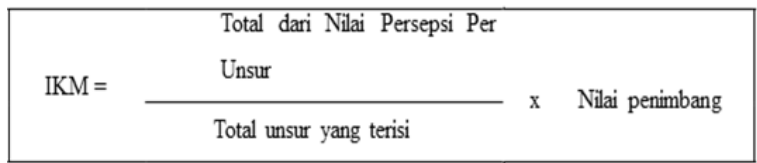

Untuk memudahkan interpretasi terhadap penilaian IKM yaitu antara 25 - 100 maka hasil penilaian tersebut di atas dikonversikan dengan nilai dasar 25, dengan rumus sebagai berikut:

\section{IKM Unit pelayanan $x 25$}

Tabel 1 Nilai Persepsi, Interval IKM, Interval Konversi IKM, Mutu Pelayanan dan Kinerja Unit Pelayanan

\begin{tabular}{|c|c|c|c|c|}
\hline $\begin{array}{l}\text { NILAI } \\
\text { PERSEPSI }\end{array}$ & $\begin{array}{c}\text { NILAI } \\
\text { INTERVAL } \\
\text { IKM }\end{array}$ & $\begin{array}{c}\text { NILAI } \\
\text { INTERVAL } \\
\text { KONVERSI } \\
\text { IKM }\end{array}$ & $\begin{array}{l}\text { MUTU } \\
\text { PELAYANAN }\end{array}$ & $\begin{array}{c}\text { KINERJA UNIT } \\
\text { PELAYANAN }\end{array}$ \\
\hline 1 & $1,00-1,75$ & $25-43,75$ & D & Tidak baik \\
\hline 2 & $1,76-2,50$ & $43,76-62,50$ & C & Kurang baik \\
\hline 3 & $2,51-3,25$ & $62,51-81,25$ & B & Baik \\
\hline 4 & $3,26-4,00$ & $81,26-100,00$ & A & Sangat baik \\
\hline
\end{tabular}

\section{HASIL}

Dari hasil keseluruhan yang dilakukan penilaian pada 17 UPT maka hasil indek kepuasan masyarakat terhadap layanan UPT
Tabel 2. Nilai Rata-Rata Unsur Pelayanan di UPT.

\begin{tabular}{|l|c|c|}
\hline \multicolumn{1}{|c|}{ Unsur Pelayanan } & Nilai Unsur Provinsi & Indek \\
\hline Persaratan Pelayanan & 3.67 & 0.41 \\
\hline Prosudure Pelayanan & 3.65 & 0.41 \\
\hline waktu Pelayanan & 3.56 & 0.39 \\
\hline Biaya & 3.62 & 0.40 \\
\hline Produk Spesifikasi Jenis Pelayanan & 3.81 & 0.42 \\
\hline Kompetensi Pelaksana & 3.72 & 0.41 \\
\hline Perilaku Pelaksanan & 3.72 & 0.41 \\
\hline Maklumat Pelayanan & 3.37 & 0.37 \\
\hline Penangan Pengaduan, Saran dan Masukan & 3.21 & 0.36 \\
\hline \multicolumn{2}{|c|}{ Nillai Indek } & 3.59 \\
\hline Nilai IKM & $\mathbf{3 9 . 7 6}$ \\
\hline Mutu Pelayanan \\
\hline
\end{tabular}

Dari hasil keseluruhan maka pelayanan UPT di lingkungan Dinas Pendapatan Provinsi adalah sangat baik dengan kategori mutu pelayanan A (sangat baik). Hal ini diperoleh dari pendapat responden dimana nilai unsur rata-rata tertinggi adalah Produk spesifikasi jenis pelayanan yang memperoleh nilai rata-rata 3.81, kemudian Kompetensi Pelaksana dan Perilaku Pelaksana yang memperoleh nilai rata-rata 3.72. begitu juga dengan persyaratan pelayanan dan prosedur pelayanan yang memperoleh nilai unsur rata-rata sebesar 3,67 dan 3,65. Nilai unsur terendah hanya pada unsur Penangan Pengaduan, Saran dan Masukan dengan nilai rata-rata 3.21.

Hal ini memang berdasarkan hasil pengamatan hanya pada beberapa UPT saja yang memberikan pelayanan cepat seperti pada UPT Pangkalan Kerinci, dimana durasi pelayanan hanya memerlukan waktu 10 menit dan pada UPT pekanbaru Kota adalah 15 menit. Pada UPT lainnya masih menggunakan hitungan waktu lebih dari 1 jam bahkan ada yang mencapai 1 hari. Selain itu unsur terendah juga ada unsur Maklumat Pelayanan dengan nilai rata-rata 3.37. Menurut responden tingkat kenyamanan masih sangat kurang pada UPT seperti kurangnya kursi tunggu, ruangan yang panas dan lainnya. 


\section{Perbandingan Nilai IKM Kabupaten Kota di Provinsi Riau}

Berdasarkan hasil pengamatan dan survey yang dilakukan terhadap 17 UPT di Lingkungan Dinas Pendapatan Provinsi Riau, maka hasil secara keseluruhan dapat dilihat pada tabel berikut ini:

Tabel 3. Nilai IKM dan Mutu Pelayanan Menurut UPT

\begin{tabular}{|c|l|c|c|}
\hline NO & \multicolumn{1}{|c|}{ UPT } & Nilai IKM & Mutu Pelayanan \\
\hline $\mathbf{1}$ & PEKANBARU SELATAN & 92,64 & $\mathrm{~A}$ \\
\hline $\mathbf{2}$ & PEKANBARU KOTA & 98,08 & $\mathrm{~A}$ \\
\hline $\mathbf{3}$ & DURI & 81,47 & $\mathrm{~A}$ \\
\hline $\mathbf{4}$ & DUMAI & 85,82 & $\mathrm{~A}$ \\
\hline $\mathbf{5}$ & PANGKALAN KERINCI & 95,35 & $\mathrm{~A}$ \\
\hline $\mathbf{6}$ & SIAK SRIINDRAPURA & 91,34 & $\mathrm{~A}$ \\
\hline $\mathbf{7}$ & RENGAT & 90,48 & $\mathrm{~A}$ \\
\hline $\mathbf{8}$ & TEMBILAHAN & 87,13 & $\mathrm{~A}$ \\
\hline $\mathbf{9}$ & TELUK KUANTAN & 93,49 & $\mathrm{~A}$ \\
\hline $\mathbf{1 0}$ & BANGKINANG & 92,16 & $\mathrm{~A}$ \\
\hline $\mathbf{1 1}$ & PASIR PENGARAIAN & 91,57 & $\mathrm{~A}$ \\
\hline $\mathbf{1 2}$ & BAGAN SIAPI-API & 78,25 & $\mathrm{~B}$ \\
\hline $\mathbf{1 3}$ & BAGAN BATU & 80,6 & $\mathrm{~B}$ \\
\hline $\mathbf{1 4}$ & BENGKALIS & 89,54 & $\mathrm{~A}$ \\
\hline $\mathbf{1 5}$ & KUBANG & 93,85 & $\mathrm{~A}$ \\
\hline $\mathbf{1 6}$ & PERAWANG & 90,94 & $\mathrm{~A}$ \\
\hline $\mathbf{1 7}$ & SELATPANJANG & 92,59 & $\mathrm{~A}$ \\
\hline & RIAU & 89,76 & $\mathrm{~A}$ \\
\hline
\end{tabular}

Berdasarkan tabel 3,19 maka nilai ratarata IKM UPT Dinas Pendapatan Provinsi Riau adalah 89,76 atau dengan kategori Mutu pelayanan A. Selanjutnya dari tabel tersebut dapat diurutkan UPT 2 terbaik dan 2 terendah yaitu :

Tabel 4 . Dua UPT Terbaik dalam Pelayanan

\begin{tabular}{|l|c|c|}
\hline \multicolumn{1}{|c|}{ UPT } & Nilai IKM & Mutu Pelayanan \\
\hline PEKANBARUKOTA & 98,08 & A \\
\hline PANGKALAN KERINCI & 95,5 & A \\
\hline
\end{tabular}

Dari tabel 3.20 bahwa UPT yang memperoleh nilai terbaik dalam pelayanan adalah UPT Pekanbaru Kota dengan total nilai IKM 98,08, menurut responden pelayanan yang diberikan sangat cepat, tepat dan biaya yang sesuai dengan prosedurnya serta ditunjang dengan fasilitas yang sangat memadai. Kemudian adalah UPT Pangkalan Kerinci dengan total nilai IKM 95,5

Tabel 5 Dua UPT Terendah dalam Pelayanan

\begin{tabular}{|l|c|c|}
\hline \multicolumn{1}{|c|}{ UPT } & Nilai IKM & Mutu Pelayanan \\
\hline BAGAN SIAPI-API & 78,25 & B \\
\hline BAGAN BATU & 80,6 & B \\
\hline
\end{tabular}

Walaupun secara keseluruhan
pelayanan UPT kategori baik namun demikian dilihat dari nilai IKM terdapat 2 UPT dengan nilai yang cukup rendah yaitu UPT Bagan siapi-api dan UPT Bagan Batu.
Pada UPT Bagan siapi-api pendapat masyarakat bahwa mereka sangat disusahkan dengan aturan yang tidak jelas dalam pelayanan sedangkan pada UPT Bagan batu system yang diterapkan masih membingungkan dan kejelasan biaya.

\section{PEMBAHASAN}

Berdasarkan persepsi masyarakat dapat terlihat bahwa, maka dapat diambil suatu kesimpulan berikut ini : Dari 9 Indikator pelayanan yang diteliti terdapat 2 indikator dengan kategori yang masih harus mendapat perhatian yaitu : Penangan Pengaduan, Saran dan Masukan serta maklumat pelayanan. Sedangkan 7 indikator sudah cukup baik. Nilai rata-rata IKM UPT Dinas Pendapatan Provinsi Riau adalah 89,76 atau dengan kategori Mutu pelayanan A. UPT yang memperoleh nilai terbaik dalam pelayanan adalah UPT Pekanbaru Kota dengan total nilai IKM 98,08, menurut responden pelayanan yang diberikan sangat cepat, tepat dan biaya yang sesuai dengan prosedurnya serta ditunjang dengan fasilitas yang sangat memadai. Kemudian adalah UPT Pangkalan Kerinci dengan nilai IKM sebesar 95,5.

UPT dengan nilai yang cukup rendah yaitu UPT Bagan siapi-siapi dan UPT bagan Batu. Pada UPT Bagian siapi-api pendapat masyarakat bahwa mereka mengeluh tidak adaya ruang pengaduan, saran dan masukan serta tidak adanya maklumat pelayanan. sedangkan pada UPT Bagan Batu selain pengaduan juga terkait dengan waktu pengurusan yang sangat lama.

Demi menjaga kepercayaan masyarakat akan pelayanan maka Aspekaspek yang harus dijadikan prioritas utama dalam perbaikan pelayanan disesuaikan dengan hasil temuan lapangan, beberapa aspek tersebut adalah : Penanganan pengaduan, keluhan dan Saran, Setiap adanya keluhan yang dirasakan oleh masyarakat, petugas diharapkan mampu mengakomodir dan memberikan bantuan secukupnya. Hal ini dirasakan sangat penting karena empati petugas terhadap keluhan masyarakat 
menjadi faktor terhadap kepuasan masyarakat pada pelayanan. Maklumat Pelayanan, adanya maklumat dan kejelasan informasi dirasakan masyarakat sangat kurang.

Hal ini perlu diperbaiki karena masyarakat dalam berurusan membutuhkan adanya kejelasan informasi. Untuk lebih jelas kebutuhan perbaikan sarana per UPT dapat kami jelaskan sebagai berikut, UPT Pekanbaru Selatan. waktu operasional yang tertib dan teratur mengingat jangkauan pelayanan cukup luas, fasilitas dan suasana gedung perlu ditingkat (pendingin dan perlengkapan), sebaiknya sarana parkir tidak dipungut bayaran karena merupakan area perkantoran pemerintah.

UPT Pekanbaru Kota, apabila menggunakan pengeras suara sebaiknya operator menyebutkan nomot loket saat memanggil wajib pajak, kenyamanan ruangan tunggu perlu ditingkatkan mengingat jumlah wajib pajak yang melakukan ativitasnya di UPT ini cukup banyak, parkir kendaraan wajib pajak diperluas, sebaiknya sarana parkir tidak dipungut bayaran karena merupakan area perkantoran pemerintah. UPT Duri, berkaitan dengan pelayanan maka kecepatan pelayanan masih harus ditingkatkan, saat ini wajib pajak membutuhkan waktu 1 hari penuh untuk urusan di UPT walaupun diakui kondisi ini jauh lebih baik dari sebelumnya dimana setiap urusan diperlukan waktu beberapa hari dalam penyelesaiannya, peningkatan SDM pegawai agar lebih produktif dalam kinerja, gedung kantor yang masih sederhana, sehingga perlu diperluas agar tidak ada antrian yang menumpuk, sarana pendukung seperti pengeras suara yang sudah selayaknya diperbaharui, dan ruang tunggu yang jauh lebih nyaman dari saat ini.

UPT Dumai, counter informasi sebaiknya lebih terbuka sehingga memudahkan Wajib pajak untuk memperoleh informasi dengan petugas yang selalu siap di tempatnya, perlu dilengkapi kotak saran dan keluhan. UPT Pangkalan Kerinci, tempat parkir masih kurang memadai dan berantakan, sehingga kedepannya perlu diperbaiki dan diatur untuk meningkatkan kenyamanan wajib pajak, kenyamanan dan fasilitas perlu ditingkatkan.

UPT SIAK, maklumat pelayanan perlu diperbaiki, berkaitan dengan sarana yang ada, infrastruktur masih kurang memadai, tempat parkir menjadi salah satu kendala dimana tempat yang tersedia masih sangat sempit, selain itu kenyamanan ruang tunggu bagi wajib pajak masih harus diperbaiki, sikap pelayan dalam melayani masyarakat perlu diperbaiki etikanya, tata Lay out perlu diperbaiki. UPT RENGAT, UPT Rengat telah memiliki gedung yang memadai serta pelayanan yang cukup baik daripada tahun sebelumnya. namun perlu perbaikan-perbaikan dalam informasi dan kemudahan dalam urusan, serta perlunya mengatasi calo-calo yang sering menawarkan bantuan kepada wajib pajak.

UPT TEMBILAHAN, Pada UPT Tembilahan terdapat beberapa hal yang harus diperbaiki yaitu berkaitan dengan waktu tunggu wajib pajak dalam urusan yang dirasakan masih lama, serta waktu operasional yang kurang sehingga banyak wajib pajak yang bertempat tinggal jauh dari UPT merasa waktu yang sangat kurang dalam pelayanan. Namun secara umum pelayanan UPT Tembilahan sangat bagus karena sudah menggunakan komputerisasi. UPT Teluk Kuantan, Perlunya sosialisasi dan upaya jemput bola bagi wajib pajak yang enggan berurusan di UPT, Fasilitas dan infrastruktur kurang memadai dan perlu ditingkatkan.

UPT BANGKINANG, Secara umum pelayanan yang diberikan oleh UPT Bangkinang sangat baik, terutama adanya inisiatif dari UPT untuk menyediakan snack bagi wajib pajak yang sedang menunggu antrian. Sarana pendukung seperti pendingin ruangan perlu diperbaiki karena terkait dengan kenyamanan wajib pajak dalam melakukan urusan. UPT PASIR PENGARAIAN, Permasalahan utama UPT Pasir Pengaraian adalah gedung yang masih kurang memadai, sehingga berdampak pada fasilitas dan sarana pendukung yang sangat kurang. Dengan antusiasnya wajib 
pajak dalam membayarkan kewajibannya, kedepannya UPT Pasir Pengaraian harus meningkatkan saran dan fasilitas kantor sehingga pelayanan bisa ditingkatkan.

UPT BAGAN SIAPI-API, Kesadaran masyarakat dalam membayar pajak sangat kurang sehingga Perlunya sosialisasi dan upaya jemput bola agar wajib pajak mematuhi aturan untuk membayar pajak, fasilitas yang tersedia masih kurang memadai dan perlu ditingkatkan. UPT BAGAN BATU, sarana pendukung seperti ruang tunggu maka tingkat kenyamanannya masih harus ditingkatkan, akses menuju kantor sangat tidak memadai, hal ini perlu diperhatikan oleh pemerintah daerah untuk memperbaiki akses menuju UPT. UPT BENGKALIS, kurangnya sosialisasi prosedur pengurusan sehingga banyak masyarakat tidak tahu dan keberatan dengan persyaratan yang ditetapkan, infrastruktur seperti toilet, mushalla tidak ada, serta parkir, kurang memadai dan perlu diperbaiki. UPT KUBANG, secara umum pelayanan yang diberikan cukup baik, namun ada beberapa hal yang dirasakan kurang seperti sarana dan prasarana serta tempat yang tidak memadai. kedepannya perlu dianggarkan untuk menggunakan gedung tersendiri.

UPT PERAWANG, prosedur dan maklumat sudah cukup baik, namun sarana dan prasarana yang perlu diperbaiki dan ditingkatkan, seperti kenyamanan dalam menggunakan toilet, mushalla serta parkir. UPT SELATPANJANG, pelayanan secara umum baik, namun minimnya masyarakat yang membayar pajak perlu dilakukan sosialiasi dan upaya menjemput bola. kondisi wilayah yang terdiri dari kepulauan membuat masyarakat keberatan untuk melakukan kewajiban membayar pajak. Hal ini perlu diantisipasi agar masyarakat/wajib pajak mudah dalam melakukan proses pembayaran.

\section{SIMPULAN}

Dari uraian dalam penelitian ini dijelaskan bahwa persepsi masyarakat dapat terlihat bahwa, maka dapat diambil suatu kesimpulan berikut ini : Dari 9 Indikator pelayanan yang diteliti terdapat 2 indikator dengan kategori yang masih harus mendapat perhatian yaitu : Penangan Pengaduan, Saran dan Masukan serta maklumat pelayanan. Sedangkan 7 indikator sudah cukup baik. Nilai rata-rata IKM UPT Dinas Pendapatan Provinsi Riau adalah 89,76 atau dengan kategori Mutu pelayanan A. UPT yang memperoleh nilai terbaik dalam pelayanan adalah UPT Pekanbaru Kota dengan total nilai IKM 98,08, menurut responden pelayanan yang diberikan sangat cepat, tepat dan biaya yang sesuai dengan prosedurnya serta ditunjang dengan fasilitas yang sangat memadai.

\section{DAFTAR RUJUKAN}

Berry, L., Zeithaml, V., Parasuraman, A. (1990) The ServiceQuality Puzzle. Business Horizons

Fandy Tjiptono, Manajemen Jasa, Penerbit Andi Yogyakarta 2000

Gaster, Lucy., 1995. Quality In Public Services. Manager's Choices. London: Open University Buckingham Philadelphia Press

K. Douglas Hoffman dan John E. G. Beteson. 2002,Essentials of Service Marketing:Concepts, Strategies, and CasesUnited States of America: Harcourt College

Kotler, Philip.1995.Manajemen Pemasaran. Jakarta. Penerbit Erlangga

Lovelock, Christopher. 2004. Service Marketing and Management. New Jersey:Prentice Hall.

Martono, Nanang. 2010. Metode Penelitian Kuantitatif Analisis Isi dan Analisis Data Sekunder, Jakarta : PT Raja Grafindo Persada.

Mowen, J. C. (1995), Consumer Behavior 4th edition. New Jersey. Prentice Hall

Martin Mendelsohn, 1998Franchising : Petunjuk Praktis Bagi Franchisor dan Franchisee, Pustaka Binaman Perssindo, Jakarta

Zauhar, Soesilo, 2001, Admiinistrasi Pelayanan Publik, Jurnal Administrasi Negara, Vol. 1 Nomor 2, 2001 